\title{
Retraction Note to: Modelling and verification of white light oil immersion microsphere optical nanoscope
}

\author{
Jinzhong Ling ${ }^{1} \cdot$ Xiaorui Wang ${ }^{1} \cdot$ Dancui $^{\mathrm{Li}^{1}} \cdot \mathrm{Xin} \mathrm{Liu}^{1}$ \\ Published online: 20 May 2020 \\ ๑) Springer Science+Business Media, LLC, part of Springer Nature 2020
}

\section{Retraction Note to: Opt Quant Electron (2017) 49:377 https://doi.org/10.1007/s11082-017-1210-5}

The authors have retracted this article (Ling et al. 2017). Upon re-review of the data, they identified errors in the simulation and theoretical analyses which affect the results and make the conclusions invalid. All authors agree with this retraction.

\section{Reference}

Ling, J., Wang, X., Li, D., Liu, X.: Modelling and verification of white light oil immersion microsphere optical nanoscope. Opt Quant Electron 49, 377 (2017). https://doi.org/10.1007/s11082-017-1210-5

Publisher's Note Springer Nature remains neutral with regard to jurisdictional claims in published maps and institutional affiliations.

The original article can be found online at https://doi.org/10.1007/s11082-017-1210-5.

Xiaorui Wang

xrwang@mail.xidian.edu.cn

1 School of Physics and Optoelectronic Engineering, Xidian University, Xi' an 710071, Shaanxi, China 